\title{
Alternative Formulas to Predict the Greatness of U.S. Presidents: Personological, Situational, and Zeitgeist Factors
}

\author{
Stewart J. H. McCann \\ University College of Cape Breton \\ Sydney, Nova Scotia, Canada
}

\begin{abstract}
Formulas to predict presidential greatness on the Maranell index were constructed for 29 presidents from Washington to L. Johnson. When a zeitgeist variable, derived from the historian A. M. Schlesinger, Jr's (1986) work on the public purpose-private interest cycle of American political history, served as the initial predictor and stepwise selection was made from a personological pool and then from a situational pool, a 6-variable formula containing 5 personological variables accounted for $91 \%$ of the greatness variance. With free stepwise regression, years served and 6 personological predictors accounted for $94 \%$ of the greatness variance. Contrary to Simonton's (1987) attributional interpretation, a dispositional basis for presidential greatness may exist. The results also suggest that public purpose phases bring forth presidents who exhibit the personological characteristics most related to historians' acclaim for presidential leadership.
\end{abstract}

What characteristics define successful leaders? What constitutes successful leadership? Because the answers are clearly of theoretical and practical importance to contexts ranging from immediate interpersonal relationships to the arena of global politics, it is not surprising that social psychologists and scholars from other disciplines have spent considerable time and energy trying to delineate the characteristics and disentangle the dynamics of successful leadership. The American presidency is a rich source of material for researching leadership in the political domain. An enormous fund of both qualitative and quantitative data is continually accumulated, and the number of presidents who have now served permits opportunities to apply relatively sophisticated quantitative and statistical strategies and techniques to the information.

One line of political leadership research has focused on the relative "greatness" of the presidents. The presidents have been formally assessed several times since 1948 by groups of experts (e.g., Chicago Tribune Magazine, 1982, cited in Murray and Blessing, 1983; Maranell, 1970; Murray \& Blessing, 1983; Porter, 1981, cited in Simonton, 1986a, 1987; A. M. Schlesinger, 1949, 1962) and by individual authorities (e.g., Bailey, 1966; Rossiter, 1956; Sokolsky, 1964). An extraordinary degree of consensus exists, with correlations between the various assessments of greatness ranging from the .70 s to the .90 s (Simonton, 1986a, 1987).

What do these ratings of merit tell us? Do presidents receive high scores because of their extraordinary capacities as political leaders? Are the greatest presidents great because they possess a certain constellation of traits important to political leadership? Are they great because of their accomplishments in office? Are they great because of the particular situational demands they face? Are they great because of their good for-

Correspondence concerning this article should be addressed to Stewart J. H. McCann, Department of Psychology, University College of Cape Breton, Box 5300, Sydney, Nova Scotia, Canada BIP 6L2. tune to serve in times that afford multifarious opportunities to display leadership while meeting the challenges of the day? Or, as Simonton (1987) concludes, do the ratings tell us more about how historians make attributions concerning the greatness of presidents than about the causes of success in the presidency?

To attempt to answer such questions, Simonton (1981, 1986a, $1986 \mathrm{~b}, 1987)$ has formulated regression equations to predict or "postdict" presidential greatness. His equations, one with five predictors and the other with six, contain number of years in office, number of war years in office, presence or absence of cabinet-level scandal, whether the president was assassinated, whether the president came to office as a national war hero, and intellectual brilliance or IQ of the president. Simonton developed the equations by using the standardized version of the most recent rating of the presidents by Murray and Blessing (1983) as the criterion. The five-variable formula comprises situational variables:

$$
\begin{aligned}
.17 \text { (years in office }) & +.26 \text { (war years) }-1.70 \text { (scandal) } \\
+ & +.89 \text { (assassinated) }+.82 \text { (war hero })-1.24
\end{aligned}
$$

The six-variable equation also includes intellectual brilliance:

$$
\begin{aligned}
& .15 \text { (years in office) }+.21 \text { (war years) }-1.44 \text { (scandal) } \\
& \quad+.73 \text { (assassinated) }+.87 \text { (war hero })+.26(\text { IQ) }-1.10
\end{aligned}
$$

Simonton (1986b) found that $78 \%$ of the variance in the Murray and Blessing (1983) ratings is accounted for by the five-variable equation and $82 \%$ is accounted for by the six-variable equation.

Simonton took the following steps to develop the equations. In his (1986a) analysis, Simonton scanned a pool of over 200 potential predictors for variables that correlated with every one of 13 greatness ratings (i.e., Bailey [1966] as transposed by Kynerd [1971]; the Chicago Tribune [cited in Murray \& Blessing, 1983]; the prestige, strength, activeness, accomplishment, and information dimensions of Maranell [1970]; Murray \& Blessing [1983]; Porter [cited in Simonton, 1986a, 1987]; Rossiter 
[1956]; Schlesinger [1949, 1962]; Sokolsky [1964]). Only years in office and years of war passed this initial screening. A third variable, the presence of cabinet-level scandal, correlated with all of the ratings but the Maranell information index. Guided by an earlier finding (Simonton, 1981), Simonton then computed partial correlations between assassination and the 13 greatness ratings with years in office controlled and found significant positive correlations for all except the Rossiter (1956) rating. Next, Simonton computed three regression equations by entering years in office, war years, scandal, and assassination as potential predictors, using the Murray and Blessing, the Porter, and the Chicago Tribune ratings as separate criterion variables. In each instance, the four variables accounted for a significant portion of the variance in greatness. To determine whether any other variables from the pool of potential predictors could be added to the regression equations, Simonton calculated correlations between the pool variables and the residuals from the three equations. Only war hero status correlated with all three residuals and was consequently added to produce five-variable regression equations. The three equations had similar regression coefficients and the scores predicted from the Murray and Blessing formula correlated with each of the three greatness ratings to the same degree. Simonton then computed new residuals for the three equations and calculated correlations with the remaining pool variables, but no other predictors surfaced. In a later analysis, Simonton (1986b) turned to 14 dimensions of presidential personality gleaned from Gough Adjective Check List assessments of biographical information and found that only intellectual brilliance correlated with all 13 greatness ratings. He accordingly added intellectual brilliance to form a six-variable equation. The predictive capacity of the Murray and Blessing (1983) six-variable equation - the ultimate formula-was marginally better with the Murray and Blessing ratings as the criterion than it was with the Porter (cited in Simonton 1986a, 1987) or the Chicago Tribune (cited in Murray \& Blessing, 1983) ratings as the criterion.

It might be argued that there are certain inconsistencies in the steps that resulted in Simonton's (1986b) six-variable equation. To begin with, none of the 14 personality variables were included in the initial pool of potential predictors. They were simply not available when Simonton's (1986a) analysis was conducted. Therefore, even though intellectual brilliance showed higher correlations with the 13 greatness ratings than did either years in office or years of war, it was not allowed to be the primary predictor. Given Simonton's rationale for selecting term length and war years as predictors, intellectual brilliance would have been the primary predictor for the Murray and Blessing (1983) criterion, for which greatness correlated .59 with intellectual brilliance, .57 with years in office, and .50 with years of war (Simonton, 1987, p. 203, pp. 197-198). Instead of being selected as the primary predictor, intelligence was added as the sixth predictor. Its consideration for entry as a sixth predictor was justified by the rationale for the selection of primary predictors-a significant correlation with each of the 13 greatness ratings - even though the third, fourth, and fifth predictors had not met this requirement.

Although referring to the possibility that one or more of the 14 personality factors might improve the prediction of greatness, Simonton (1987) states that "it happens that just one di- mension correlates consistently by whichever criterion we choose-intellectual brilliance" (p. 203). So, it is implied that there were other personality dimensions that correlated with at least some of the greatness ratings. Regardless of whether there were significant correlations, ideally, should the other personality dimensions not have been afforded the possibility of inclusion by examining the correlations between the personality dimensions and the residuals for the three equations after the addition of each new predictor? Of course, this may not have been practical because the personality scores were unavailable at the time that the initial analyses were performed. Also, considering that assassination entered Simonton's equations because it correlated with most greatness measures after controlling for the effects of term length through partial correlation, should not other pool variables, as well as the personality variables, have been allowed a similar opportunity? Again, the lack of personality scores prevented this ideal tack.

Simonton's (1986b) claim that his five-variable equation accounts for $78 \%$ of the variance in the Murray and Blessing (1983) ratings is true but somewhat misleading in light of the development of his six-variable equation. Simonton (1986b) reported that the addition of intelligence increased the variance accounted for in the Murray and Blessing index from 78\% (adjusted $R^{2}=.74$ ) to $82 \%$ (adjusted $R^{2}=.79$ ). With raw data provided to me by Simonton, I replicated these results exactly (except for very small rounding errors) using a simultaneous regression solution. When I performed a stepwise solution, the same six variables accounted for the same amount of variance in the Murray and Blessing ratings as Simonton had reported, and the regression coefficients were identical to those of the earlier investigation. However, in the stepwise solution, intelligence was entered into the equation first and accounted for $36 \%$ of the variance in the criterion. Therefore, the other five predictors accounted for an additional $46 \%$ rather than $78 \%$ of the variance in greatness. In other words, if intelligence, a variable known to be important to successful leadership, is statistically controlled, Simonton's five-variable equation loses $41 \%$ of its predictive capacity.

Generally speaking, predictors already in a regression equation can profoundly determine which other variables from a pool will maintain or develop the capacity to account for variance in the dependent variable (Nunnally, 1967). Because Simonton, perhaps of necessity, did not give personality variables a primary role in the construction of regression equations, and because the predictors that form the equations are by and large of a situational nature, one is left with the impression that personality variables are relatively unimportant as greatness predictors. Furthermore, Simonton interprets his equations within an attributional rather than a personal framework. Instead of viewing great presidents as possessing traits that are essential for excelling in the White House or asking "what a president did to deserve to be called great, the attributional interpretation concentrates our attention on the information-processing strategies and heuristic methods that a historian uses to infer the attribute of leader greatness" (Simonton, 1987, p. 210).

Simonton concludes that the regression equations are composed of the actual variables that historians use more or less intuitively, according to the general principles of person perception, to make dispositional attributions concerning the relative 
greatness of U.S. presidents (e.g., Simonton, 1987, p. 203). But if somewhat different approaches were taken in the process of construction of equations, perhaps formulas with quite different variables but comparable or even greater predictive powers might emerge. If this were to happen, Simonton's attributional interpretation might be disputed.

The current study was primarily initiated to develop alternative regression equations to predict presidential greatness wherein potential personological predictors would have a better chance to demonstrate their impact. More specifically, the research plan was (a) to formulate separate personological and situational equations and to compare their predictive capacities both with each other and with the Simonton equations, (b) to determine whether personological variables may indeed play a major role in accounting for the variance in greatness when they are allowed to enter the predictive equation before situational variables, and (c) to develop an equation with maximal predictive capacities that uses personological and situational variables. I also (d) sought to determine whether a zeitgeist variable-the public purpose-private interest cycle of American political history (A. M. Schlesinger, Jr., 1986) -could add to the predictive utility of personological and situational variables in regard to presidential greatness.

Psychometrically sound estimates of presidents' standings on personality dimensions are not abundant, of course, but such scores can be taken from two notable sources: (a) Winter's (1987) estimates of presidents' power, achievement, and affiliation motives as determined from the content analysis of inaugural addresses and (b) Simonton's (1986b) assessments of presidential personality through biographical use of the Gough Adjective Check List. Height was also included in the current personological roster because it has frequently been related to leadership (e.g., Keyes, 1980) and correlates with presidential greatness (Simonton, 1981).

As noted earlier, Simonton's (e.g., 1981, 1986a, 1986b, 1987) rather extensive search for variables that might predict presidential greatness has resulted in five situational variables surfacing as somewhat independent contributors: the length of the president's term in office, the number of war years that the president served in office, whether there was a major scandal during his tenure in office, whether the president was a war hero before coming to office, and whether the president was assassinated in office. Given the extensive research carried out by Simonton to uncover these variables, only these five were included in the present situational pool.

The zeitgeist variable was derived from the work of the American historian A. M. Schlesinger, Jr. (1986). According to Schlesinger, there is a 30 -year alternation between public purpose and private interest concerns in the political history of the United States. The public purpose phase is characterized by passion, idealism, heightened political commitment, a great deal of change, and a broad effort to improve society. The private interest phase, in contrast, is rampant with hedonism, materialism, relentless pursuit of personal gratification, and the general notion that a freer market and increased privatization can cure contemporary societal ills. Schlesinger sees the ebb and flow as a genuine cycle, with approximately 15 years of turbulent public purpose politics being inevitably followed by approximately 15 years marked by the politics of private interest.

A. M. Schlesinger, Jr's (1986) public purpose-private interest cycle can be regarded as an index of zeitgeist. Zeitgeist refers to the spirit of the time, to the trend of feeling and thought in any age or epoch, and to the moral and intellectual proclivities that dominate a period of history. Clearly, A. M. Schlesinger, Jr's "cycles of American history" are not focused on a narrow political spectrum but on recurring changes in the spirit of the times. A. M. Schlesinger, Jr. broadly defines his cycle "as a continuing shift in national involvement" $(1986$, p. 27$)$. Shifts in the cycle affect the national mood and alter the fabric of social existence.

Historical and political science literature "is practically unanimous on the point that crises are essential to presidential greatness" according to Nice $(1984$, p. 445$)$, and "to occupy the White House during tranquil, well-ordered times is to have little opportunity for developing a reputation of greatness" ( $p$. 446). In fact, Simonton (1987) too acknowledges this assumption:

The nation's leader must have the opportunity to prove his mettle, and this requires a crisis, whether foreign or domestic. It may even be true that all presidents are essentially the same in raw character and skill but that some are made great by their times. (p. 194)

Although Simonton $(1981,1986 \mathrm{a}, 1987)$ has found that years of war-a crisis variable-is rather strongly related to greatness, no zeitgeist variable such as Schlesinger's was included in Simonton's predictor pool. A. M. Schlesinger, Jr's cycle appears to fit the need for a variable spanning the course of American presidential history that gauges the degree to which there is national crisis and upheaval. One might expect that if crises are essential to the achievement of greatness in the eyes of historians, then greatness should be associated with serving during public purpose phases.

\section{Method}

\section{Presidential Greatness}

I used the Maranell (1970) ratings, as derived by Simonton (1981), as the greatness criterion. As Simonton (1987) has pointed out, the Maranell ratings are superior in terms of methodological sophistication: "Although the Murray and Blessing (1983) study is more current, the type of scaling found in the Maranell (1970) survey remains perhaps the best of the lot" (pp. 174-175). The Maranell ratings correlate as well $(r=.92)$, on the average, with the previous ratings by A. M. Schlesinger (1949, 1962), Rossiter (1956), and Sokolsky (1964) as do the Murray and Blessing ratings with these earlier ratings $(r=.91)$. Because Simonton has extensively researched the correlates and predictors of the Murray and Blessing ratings, more analyses with the Maranell ratings seem to be worthwhile to determine the generalizability of Simonton's findings. Note also that, given the completeness of the scores in the present potential predictor pool, using the Murray and Blessing ratings would increase the effective sample size only from 29 to 31 . In any case, for comparison purposes, I also constructed regression equations with the Murray and Blessing ratings as the criterion.

In addition to the Maranell (1970) and the Murray and Blessing (1983) ratings, six other standardized assessments of presidential greatness provided by Simonton (1987, pp. 182-183) served as criteria with which to compare the relative predictive capacities of the various equations developed in the current study and by Simonton. The ratings 
are based on those of A. M. Schlesinger $(1949,1962)$, Rossiter (1956), Sokolsky (1964), the Chicago Tribune Magazine (1982, cited in Murray \& Blessing, 1983), and Porter (1981, cited in Simonton, 1986a, 1987). Ratings by Bailey (1966) and transposed by Kynerd (1971) were also tabled by Simonton but are markedly out of line with the other indexes, and Simonton (1987) has alluded to their cantankerous nature. Consequently, I excluded the Bailey-Kynerd ratings from these analyses.

\section{Personological Dimensions}

For power, achievement, and affiliation motives, standardized scores based on the content analysis of inaugural addresses were taken from Winter (1987, p. 198). Complete data were available for all of the presidents from Washington through Reagan with the exception of Tyler, Fillmore, A. Johnson, Arthur, and Ford.

Simonton's (1986b, p. 154) standardized scores for 14 personality factors derived from an application of the Gough Adjective Check List technique to biographical material composed the majority of the personological pool variables. Simonton isolated intellectual brilliance, achievement drive, forcefulness, inflexibility, moderation, friendliness, poise and polish, wit, tidiness, conservatism, pacificism, pettiness, Machiavellianism, and physical attractiveness.

The heights of the presidents from Washington to L. Johnson, with the exception of Wilson, were obtained from Kane (1964). Heights for Wilson, Nixon, Ford, and Carter were taken from miscellaneous sources and may not be seen as official (i.e., Wilson, $6^{\prime}$; Nixon, 5' 10"; Ford, $6^{\prime}$; Carter, $\left.5^{\prime} 10^{\prime \prime}\right)$.

\section{Situational Variables}

Simonton's (1987, p. 201) five situational predictors constituted the pool. The length of the president's term in years was calculated to two decimal places. The number of war years that the president served in office was calculated to two decimal places from information provided by Nice (1984, p. 449) and from exact duration dates for American involvement taken from several sources (i.e., Bemis, 1955, 1959; Encyclopedia Americana, 1984; Kane, 1964; Leckie, 1968; Matloff, 1969). Included were the naval war with France (1798-1800), the First Barbary War (1801-1805), the Second Barbary War (1815), the War of 1812, the Mexican War, the Civil War, the Spanish-American War, Mexican-American border clashes (1914-1917), World War I, World War II, the Korean War, and the Vietnam conflict. This operational definition of war differs somewhat from the one used by Simonton, who used whole numbers to indicate the years or parts of years that the United States was at war. ${ }^{1}$ The presence of scandal at the cabinet level was scored 1 for Grant, Harding, and Nixon and 0 for the others on a dummy-coded variable. A second dummy-coded variable indicated assassination, with a 1 for Lincoln, Garfield, McKinley, and Kennedy and a 0 otherwise. Simonton's war heroes (i.e., Washington, Jackson, W. Harrison, Taylor, Grant, T. Roosevelt, and Eisenhower) were identified with a $l$ and all others were identified with a 0 on a third dummycoded variable.

\section{Zeitgeist}

A. M. Schlesinger, Jr. (see also Morrow, 1987; A. M. Schlesinger, 1949) classified the years from 1789 to 1986 as in Table 1 . Because A. M. Schlesinger, Jr.'s variable had not been used in this context before, I used three different operationalizations to guard against overlooking its potential impact. I created one variable, Zeitgeist 1, by giving each year in a president's tenure, and fraction of a year to two decimal places, appropriate weightings (i.e., 1, 2, or 3 for private interest, transition, or public purpose, respectively) and summing the resulting values. Zeitgeist 2 indicated the number of years to two deci-
Table 1

A. M. Schlesinger, Jr.'s (1986) Years of Private Interest, Transition, and Public Purpose

\begin{tabular}{ccc}
\hline Private interest & Transition & Public purpose \\
\hline $1789-1800$ & $1801-1802$ & $1803-1815$ \\
$1818-1828$ & $1816-1817$ & $1831-1840$ \\
$1843-1860$ & $1829-1830$ & $1863-1868$ \\
& $1841-1842$ & $1903-1918$ \\
$1871-1900$ & $1861-1862$ & $1933-1946$ \\
$1921-1930$ & $1869-1870$ & $1962-1971$ \\
$1949-1959$ & $1901-1902$ & \\
$1974-1986$ & $1919-1920$ & $1931-1932$ \\
\hline
\end{tabular}

mal places that the president served in the public purpose phase. Zeitgeist 3 carried the percentage (to one decimal place) of the president's tenure that fell in the public purpose phase of the cycle. For the second and third variables, the two transition years were divided into public purpose and private interest years.

\section{Procedure and Results}

I selected a maximum common database in which there were no missing data on the 18 personological, 5 situational, and 3 zeitgeist variables and in which the Maranell and the Murray and Blessing ratings provided scores for every president. This database $(n=29)$ included all of the presidents from Washington to L. Johnson with the exception of W. Harrison, Tyler, Fillmore, A. Johnson, Garfield, and Arthur.

For this common database, the Maranell (1970) and the Murray and Blessing (1983) ratings were highly correlated $(r=$ .96). The following variables correlated with the Maranell index at the .05 level or better: Zeitgeist I (.70), Zeitgeist 2 (.67), IQ (.67), war years (.63), Zeitgeist 3 (.62), forcefulness (.61), achievement drive (.59), conservatism (-.57), length of term (.54), height (.49), moderation (-.48), power (.41), and scandal (-.39). For comparison, the significant correlations with the Murray and Blessing ratings were: IQ (.66), Zeitgeist $1(.65)$, war years (.62), achievement drive (.61), Zeitgeist $2(.58)$, length of term (.56), conservatism (-.52), forcefulness (.52), Zeitgeist $3(.49)$, scandal (-.46), height (.45), and moderation $(-.40)$.

Using the selected common database $(n=29)$, I used stepwise regression (e.g., Cohen \& Cohen, 1975; Darlington, 1972; Myers, 1979) to predict the Maranell scores from the pool of personological variables. The following formula emerged:

$$
\begin{aligned}
.42(\text { IQ })+.15 \text { (height })- & .24 \text { (attractiveness) }-.33 \text { (tidiness) } \\
+ & .32 \text { (achievement drive) }-10.29 .
\end{aligned}
$$

This personological formula accounted for $82.4 \%$ (adjusted $\left.R^{2}=.79\right)$ of the variance in the Maranell (1970) index, $F(5,23)$ $=21.46, p<.001$. IQ alone accounted for $44.9 \%$ of the variance in greatness, $F(1,27)=21.98, p<.001$. With the Murray and Blessing (1983) ratings as the criterion, a similar equation was produced that contained the same variables but in the follow- 
ing order: IQ, achievement drive, tidiness, height, and attractiveness. This equation accounted for $76.8 \%$ (adjusted $R^{2}=.72$ ) of the variance in greatness.

When the variables in the situational pool were selected stepwise with the Maranell (1970) ratings as the criterion, the following formula resulted:

.24 (war years) +.18 (years in office) -1.04 (scandal)

$$
+.87 \text { (assassinated) }-1.21 \text {. }
$$

This situational equation accounted for $64.9 \%$ (adjusted $R^{2}=$ .59) of the variance in greatness, $F(4,24)=11.11, p<.001$. Years of war accounted for $39.9 \%$ of the variance in greatness, $F(1,27)=17.95, p<.001$. The Murray and Blessing (1983) ratings produced an equation containing war years, scandal, and war hero status that accounted for $66.7 \%$ (adjusted $R^{2}=$ .63) of the variance in greatness.

With the Maranell (1970) ratings, when situational variables were allowed to enter the five-variable personological equation stepwise after the personological variables had been entered stepwise, only length of term accounted for further greatness variance. Term length added an increment of $9.0 \%, F(1,22)=$ $22.99, p<.001$, to raise the total variance accounted for in greatness by the six-variable equation to $91.4 \%$ (adjusted $R^{2}=$ .89). The addition of length of term to the Murray and Blessing (1983) equation increased the variance in greatness accounted for to $88.2 \%$ (adjusted $R^{2}=.85$ ).

To develop a personological and situational equation with maximal predictive capacities with the fewest number of predictors, I selected variables from the combined personological and situational pools in a free stepwise fashion with the Maranell (1970) index as the dependent variable. The following formula was produced:

$$
\begin{array}{r}
.37(\mathrm{IQ})+.13 \text { (years in office) }+.30 \text { (achievement drive) } \\
-.30 \text { (tidiness) }+.12 \text { (height) }-.23 \text { (attractiveness) } \\
+.16 \text { (Machiavellianism) }-9.31 .
\end{array}
$$

The overall equation accounted for $93.8 \%$ (adjusted $R^{2}=.92$ ) of the variance in greatness, $F(7,21)=45.46, p<.001$. IQ accounted for $44.9 \%$ of the variance, $F(1,27)=21.98, p<.001$. Years in office accounted for an additional $15.9 \%$ of the variance, $F(1,26)=10.56, p<.01$. Achievement drive accounted for a further $11.2 \%, F(1,25)=10.03, p<.01$. Another $9.9 \%, F(1,24)$ $=13.12, p<.001$, was accounted for by tidiness; another $6.1 \%$, $F(1,23)=11.62, p<.01$, by height; another $3.4 \%, F(1,22)=$ $8.64, p<.01$, by attractiveness; and a final increment of $2.4 \%$, $F(1,21)=8.28, p<.01$, by Machiavellianism. A similar equation accounted for $92.0 \%$ (adjusted $R^{2}=.89$ ) of the variance in the Murray and Blessing (1983) ratings. The order of the predictors was the same but Machiavellianism was dropped and the achievement motive was inserted (with a negative coefficient) between tidiness and height:

$$
\begin{aligned}
.36(\mathrm{IQ})+.17 \text { (years in office })+.35 \text { (achievement drive) } \\
-.26 \text { (tidiness) }-.02 \text { (achievement motive) } \\
\quad+.10 \text { (height) }-.21 \text { (attractiveness) }-6.53 \text {. }
\end{aligned}
$$

Could the A. M. Schlesinger, Jr. (1986) public purpose-private interest cycle enhance equations that are based on personological and situational factors? How should the equation be formed? What is the most logical order of entry for the personological, situational, and zeitgeist variables? It might be argued that the A. M. Schlesinger, Jr. zeitgeist factor sets the stage for a politician with certain personological characteristics to assume the presidency, and the tenor of the times combined with the president's personological characteristics results in certain administrative outcomes such as the length of term, whether war is waged, whether scandal plagues the presidency, and perhaps even whether the president is assassinated. These are, of course, four of Simonton's five situational predictors. With this line of thinking, it might be more appropriate to view war hero status as a personological variable-something the president brings to the office. According to this logical order of entry, with the Maranell index as the criterion, the following six-variable formula was produced:

$$
\begin{aligned}
& .05 \text { (Zeitgeist 1) }+.36 \text { (achievement drive) }-.25 \text { (tidiness) } \\
& +.27 \text { (IQ) }+.11 \text { (height) }-.21 \text { (attractiveness) }-7.77 \text {. }
\end{aligned}
$$

This regression equation accounted for $90.8 \%$ (adjusted $R^{2}=$ .88 ) of the variance in greatness, $F(6,22)=36.20, p<.001$. Zeitgeist accounted for $49.5 \%$ of the greatness variance, $F(1$, $27)=26.48, p<.001$. Achievement drive accounted for an additional $24.9 \%$ of the greatness variance, $F(1,26)=25.30$, $p<.001$. Tidiness, $\mathrm{IQ}$, height, and attractiveness contributed further increments of between $4.6 \%$ and $3.4 \%$. The same equation was produced whether war hero status was seen as a personological or a situational variable.

When this logical order of entry was used with the Murray and Blessing (1983) ratings as the criterion, a five-variable equation surfaced that accounted for $85.4 \%$ (adjusted $R^{2}=.82$ ) of the greatness variance. Zeitgeist accounted for $42.3 \%$ of the greatness variance and achievement drive contributed another $28.0 \%$. However, instead of including tidiness, intellectual brilliance, height, and attractiveness, this analysis appended assassination, war hero status, and years of war, which accounted for additional increments of $6.0 \%, 4.5 \%$, and $4.7 \%$ of the greatness variance.

To determine the correlates of the predictors in the various regression equations, I computed correlations between each of the predictors and the Zeitgeist 1 variable, the variables in the personological pool, and the variables in the situational pool, using the common database $(n=29$; see Table 2$)$.

Partial correlations also revealed that years in office was not correlated with greatness when Zeitgeist 1 was taken into account, $r_{p}(26)=-.02$, but zeitgeist remained correlated with greatness when years in office was controlled, $r_{\mathrm{p}}(26)=.54, p<$ .01 . Clearly, it is not simply years in office but years in office in the public purpose phase that relates to greatness.

To facilitate comparisons, I included correlations between the various greatness ratings and scores predicted from the Maranell five-variable personological formula, four-variable situational formula, six-variable personological-situational formula, seven-variable personological-situational formula, zeitgeist-first six-variable formula, Simonton five-variable formula, and Simonton (1986b) six-variable formula in Table 3. 
Table 2

Correlates of Predictors in the Various Equations

\begin{tabular}{|c|c|c|}
\hline $\begin{array}{l}\text { Equation } \\
\text { variable }\end{array}$ & Correlate & $r$ \\
\hline \multirow[t]{6}{*}{ IQ } & Years of war & .54 \\
\hline & Conservatism & -.53 \\
\hline & Achievement drive & .45 \\
\hline & Zeitgeist $1^{a}$ & .46 \\
\hline & Scandal & -.42 \\
\hline & Forcefulness & .39 \\
\hline \multirow[t]{3}{*}{ Achievement drive } & Scandal & -.66 \\
\hline & IQ & .45 \\
\hline & Power & .38 \\
\hline Tidiness & Pacifism & .52 \\
\hline \multirow[t]{3}{*}{ Height } & Wit & .44 \\
\hline & Friendliness & .42 \\
\hline & Zeitgeist 1 & .38 \\
\hline \multirow[t]{2}{*}{ Attractiveness } & Friendliness & .67 \\
\hline & Inflexibility & -.46 \\
\hline \multirow{2}{*}{\multicolumn{3}{|c|}{$\begin{array}{l}\text { Machiavellianism } \\
\text { Achievement motive }\end{array}$}} \\
\hline & & \\
\hline \multirow{2}{*}{ Years in office } & Zeitgeist 1 & .77 \\
\hline & Years of war & .37 \\
\hline \multirow[t]{5}{*}{ Years of war } & Zeitgeist 1 & .56 \\
\hline & IQ & .54 \\
\hline & Conservatism & -.42 \\
\hline & Power motive & .39 \\
\hline & Years in office & .37 \\
\hline \multirow[t]{2}{*}{ Scandal } & Achievement drive & -.66 \\
\hline & IQ & -.42 \\
\hline Assassinated & Wit & .40 \\
\hline War hero status & Pacifism & -.40 \\
\hline \multirow[t]{6}{*}{ Zeitgeist 1} & Years in office & .77 \\
\hline & Years of war & .56 \\
\hline & Conservatism & -.55 \\
\hline & Forcefulness & .50 \\
\hline & IQ & .46 \\
\hline & Height & .38 \\
\hline
\end{tabular}

Note. All displayed correlates are significant at the .05 level or better. ${ }^{a}$ For a clearer presentation, all correlations involving Zeitgeist 2 and Zeitgeist 3 have been excluded from this table.

The correlations in Table 3 were computed using a maximum common database $(n=24)$ so that the comparisons of the various equations could be made with the particular presidents being rated remaining constant. Table 3 also contains a composite index of greatness that is the sum of the eight other standardized ratings. In examining correlations between the greatness ratings and scores predicted from each of the equations formulated in this study, I found that the Murray and Blessing (1983) seven-variable personological-situational equation containing IQ, length of term, achievement drive, tidiness, achievement motivation, height, and attractiveness perhaps has the most potent predictive capacities overall. Therefore, scores predicted from this formula are also included in Table 3.

From Table 3 , it can be seen clearly that personological predictors can account for more of the variance in greatness than situational predictors. In fact, with one minor exception, the five-variable personological, the six-variable personological-situational, and the seven-variable personological-situational equations created here accounted for more of the variance in the composite index and each of the other eight greatness rat- ings than did Simonton's (1986a) five-variable equation, the four-variable situational equation formulated in this study, or even Simonton's (1986b) six-variable equation. The minor exception occurred when the six-variable Simonton formula correlation $(r=.89)$ exceeded the five-variable personological formula correlation $(r=.88)$, with the Porter (cited in Simonton, 1986a, 1987) ratings as the criterion. The zeitgeist-first six-variable formula, without incorporating any of Simonton's predictors, also exceeded the variance-accounting capacities of both Simonton equations in all cases.

Correlations between the predicted scores from the eight equations and the nine greatness ratings, based on the maximum number of presidents available for each greatness rating, are shown in Table 4 . For each rating, all of the cases with no missing data on the rating or on the predictors were included. Some caution should be exercised in making comparisons between the performance of the various formulas with information from this table because the presidents being rated differ across the greatness ratings. Nevertheless, with cautious interpretation, on the average, the Simonton (1986b) six-variable equation was surpassed only by the seven-variable personological-situational formula developed on the basis of the Murray and Blessing (1983) ratings and was equalled only by the sevenvariable personological-situational formula developed on the Maranell index. However, if one excludes the Porter (cited in Simonton, 1986a, 1987), the Chicago Tribune (cited in Murray \& Blessing, 1983), and the Murray and Blessing ratings, a much different picture is presented. With these exclusions, the performance of both Simonton equations was equaled or eclipsed by all of the equations constructed in this study except the fourvariable situational formula. Because the Simonton equations were constructed on the basis of the Murray and Blessing, the Chicago Tribune, and the Porter ratings, one might expect the formulas to be most successful with these ratings.

Do the equations developed in this research show transhistorical invariance? For example, do they predict greatness as well for the 19 th as they do for the 20th century? For the greatness ratings on which they were calculated, using the common database $(n=29)$, the residuals for the six new equations were correlated with a variable containing the order of the presidencies. Without exception, the correlations were nonsignificant. Therefore, there was no systematic tendency for the equations to overestimate or underestimate greatness according to the order of tenure. The absolute values of the residuals were then correlated with the order variable. Again, all correlations were nonsignificant, indicating that the predictions are as accurate for earlier presidents as they are for later ones. To determine whether the individual impact of each predictor has remained constant over the years, I added a variable indicating the order of the presidents and Predictor $\times$ Order terms to each of the equations to test for Order $\times$ Predictor interactions $(n=29)$. Order did not contribute to the variance accounted for in greatness with any of the six equations. Only one small interaction surfaced: Attractiveness interacted with order in the six-variable and seven-variable personological-situational equations with the Maranell (1970) criterion but accounted for additional increments of only $1.6 \%$ and $1.3 \%$ to the variance accounted for in greatness. This may be related to the fact that attractiveness was one of the few variables that correlated with order in Simonton's 
Table 3

Correlations Between Greatness and Scores Predicted From New

Equations and Simonton Equations $(n=24)$

\begin{tabular}{lcccccccc}
\hline \multicolumn{1}{c}{$\begin{array}{c}\text { Greatness } \\
\text { rating }\end{array}$} & P5 & S4 & PS6 & PS7 & Z6 & Sim5 & Sim6 & MBPS7 \\
\hline Composite & .92 & .79 & .94 & .96 & .94 & .85 & .88 & .96 \\
A. M. Schlesinger 1949 & .89 & .75 & .92 & .92 & .90 & .80 & .83 & .94 \\
Rossiter 1956 & .90 & .66 & .89 & .91 & .90 & .74 & .79 & .90 \\
A. M. Schlesinger 1962 & .88 & .76 & .90 & .91 & .89 & .82 & .86 & .93 \\
Sokolsky 1964 & .92 & .78 & .93 & .95 & .95 & .83 & .87 & .93 \\
Maranell 1970-Simonton & & & & & & & \\
$\quad$ 1981 & .92 & .80 & .95 & .97 & .96 & .85 & .88 & .95 \\
Porter (cited in Simonton, & & & & & & & & \\
$\quad$ 1986a, 1987) & .88 & .79 & .91 & .93 & .90 & .86 & .89 & .94 \\
Chicago Tribune (cited in & & & & & & & & \\
$\quad$ Murray \& Blessing, 1983) & .89 & .79 & .92 & .93 & .91 & .86 & .88 & .93 \\
Murray \& Blessing 1983 & .91 & .81 & .94 & .95 & .93 & .87 & .90 & .96 \\
$\quad M$ & .90 & .77 & .92 & .94 & .92 & .83 & .86 & .94 \\
\hline
\end{tabular}

Note. P5 and S4 refer to the personological and situational equations, respectively. PS6 refers to the 6-variable personological-situational equation. PS7 refers to the 7-variable personological-situational equation. Z6 refers to the 6-variable equation with the zeitgeist variable entered first. Sim5 and Sim6 refer to the Simonton 5-variable (1986a) and 6-variable (1986b) equations. MBPS7 refers to the 7-variable personological-situational equation developed with the Murray and Blessing (1983) ratings as the criterion. * The scores predicted from the Simonton 5-variable and 6-variable equations were computed using Simonton's operational definitions of the predictors, as provided during the review process.

(1986b, p. 151) analysis. With this very minor exception, all of the equations developed in this study appear to be transhistorically invariant.

\section{Discussion}

The current analysis has shown that alternative regression equations can account for at least as much of the variance in presidential greatness as the equations put forth by Simonton (1986a, 1986b, 1987). Furthermore, the alternative equations can be constructed entirely from personological variables, or at the least, the equations can have substantial input from personological dimensions. None of Simonton's situational predictors need to be included to produce equations with comparable or superior variance-accounting capacities. It seems that contrary to Simonton's view, a dispositional basis for greatness may indeed exist after all, providing grounds to dispute his attributional interpretation of historians' ratings.

The following five-variable personological formula, on the average, accounted for $81 \%$ of the variance in the nine indexes of greatness for the presidents included in the selected common database $(n=24)$ :

$$
\begin{aligned}
.42(\mathrm{IQ})+ & .15 \text { (height) }-.24 \text { (attractiveness) } \\
& -.33 \text { (tidiness) }+.32 \text { (achievement drive) }-10.29
\end{aligned}
$$

Compared with the Simonton equations, this personological formula showed superior performance with all of the greatness ratings except Porter's (cited in Simonton, 1986a, 1987), for which the Simonton six-variable equation accounted for $79 \%$ of the variance in greatness and the five-variable personological formula accounted for $77 \%$ of the variance. Only length of term could account for further variance in greatness, to raise the mean variance in greatness accounted for to $85 \%$. Therefore, on the average, personological variables claimed $95 \%$ of the total variance accounted for in greatness scores when they were entered into the equation before situational predictors.

It is evident that the foregoing five-variable personological formula has adequate predictive capacities, but is it readily interpretable? As Simonton (1987) pointed out when referring to his own equations, "it is one thing to predict greatness, quite another to comprehend the basis of greatness" (p. 209). With plausible interpretation as the focus, I look at each of the predictors in this formula.

There is little difficulty in accepting intellectual brilliance as the initial predictor. It correlated to a higher degree, using the common database $(n=29)$, than any other situational or personological pool variable with the Maranell (1970) rating $(r=$ $.67)$ and the Murray and Blessing (1983) index $(r=.66)$. The leadership literature is replete with references to the importance of intelligence to successful leadership (e.g., Mann, 1959; Yukl, 1981) and, more specifically, Simonton (1987, p. 210) states that "the place of intellectual brilliance in achieved greatness can be deduced from a genius theory of political leadership" (Simonton, 1984).

The second predictor, height, presents no real surprise because it has often been related to successful leadership (e.g., Keyes, 1980) and has been found to correlate with presidential greatness in the work of Simonton (1981) and in the present research. From Table 2 it can be seen that height is positively correlated with wit and friendliness. In the factor analysis carried out by Simonton (1986b, p. 159), wit was positively correlated with being self-confident, another of Yukl's (1981) successful leader characteristics. The friendliness factor (Simonton, 1986b, p. 159) may also relate to several of Yukl's successful leader characteristics such as being socially skilled, alert 
Table 4

Correlations Between Greatness and Scores Predicted From New

Equations and Simonton Equations (Maximum n)

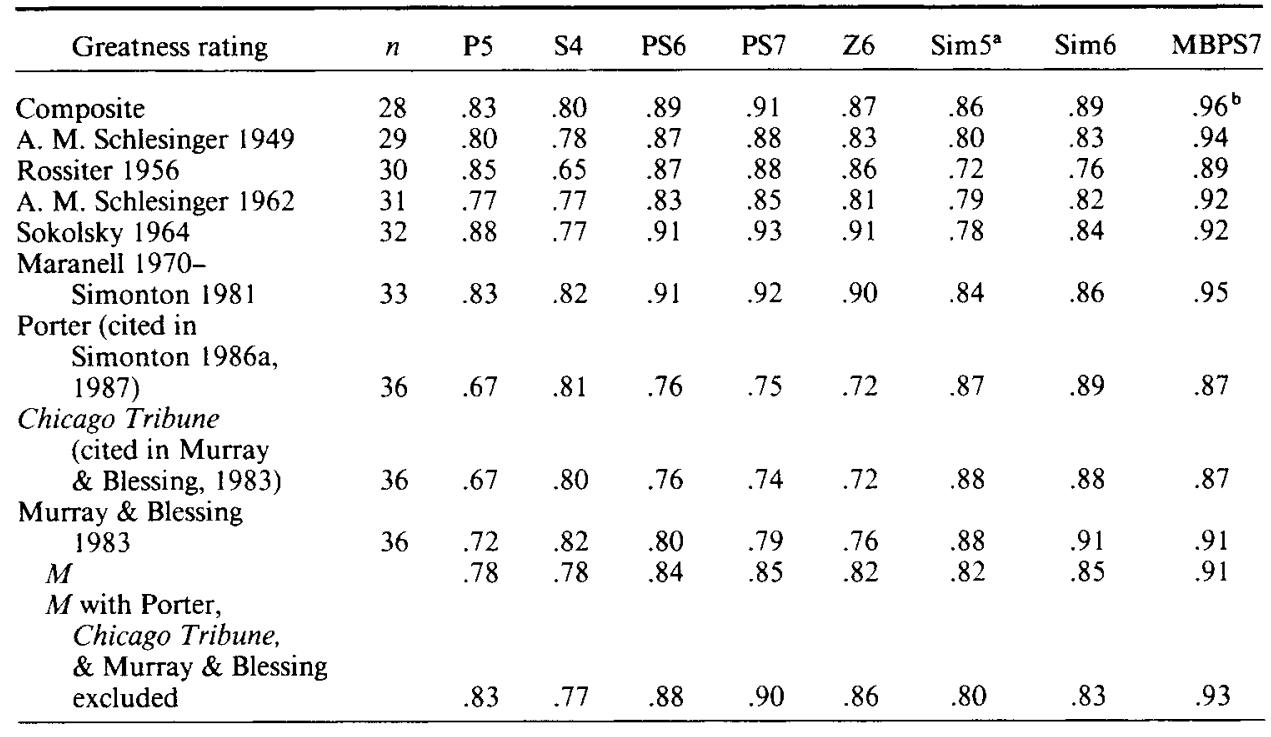

Note. P5 and S4 refer to the personological and situational equations, respectively. PS6 refers to the 6-variable personological-situational equation. PS7 refers to the 7-variable personological-situational equation. Z6 refers to the 6-variable equation with the zeitgeist variable entered first. Sim 5 and Sim6 refer to the Simonton 5-variable (1986a) and 6-variable (1986b) equations. MBPS7 refers to the 7-variable personological-situational equation developed with the Murray and Blessing (1983) ratings as the criterion. ${ }^{a}$ The scores predicted from the Simonton 5-variable and 6-variable equations were computed using Simonton's operational definitions of the predictors, as provided during the review process. ${ }^{\mathrm{b}}$ The $n$ for this column is 4 less than indicated except for the last three ratings in which the $n$ is 5 less than indicated. This anomaly occurs because the equation includes the achievement motive variable, which is not available for 5 presidents.

to the social environment, persuasive, diplomatic, and tactful. The ideal president is expected to display extraversion, persuasiveness, and a genuine interest in people (Kinder, Peters, Abelson, \& Fiske, 1980; Merenda, 1964).

Attractiveness, the third predictor, provides a somewhat more difficult interpretational challenge. Attractiveness relates to greatness in a negative fashion. Therefore, the preceding account of the indirect connection between friendliness and greatness cannot be instituted with attractiveness as it was with height. It is conceivable, though, that most of the variance in greatness that might be attributable to friendliness may have already been accounted for through the previous height predictor, so that the relationship of attractiveness to greatness is not dependent on the link between friendliness and attractiveness. Inflexibility is the only other variable significantly correlated with attractiveness (see Table 2) and the direction is negative. This makes sense because inflexibility is associated with dominance and persistence (Simonton, 1986b, p. 152, p. 160) and they are in turn included in Yukl's (1981) list of successful leader traits.

The fourth predictor, tidiness, may not at first suggest a plausible link to greatness. However, from Table 2, only one variable, pacifism, correlates with tidiness and this correlation may provide a strong clue. If one refers to Simonton's (1986b, p. 160) factor loadings, it can be seen that tidiness and pacifism are also both associated with less courage. Therefore, tidiness may bear a negative relationship to greatness in the equation at least in part because presidents who exhibit a high degree of tidiness tend to behave in a less courageous manner than less tidy and less pacifistic presidents and the ideal president is expected to display courage (Kinder et al., 1980; Merenda, 1964).

The final predictor, achievement drive, presents few problems. As with intellectual brilliance, it too correlated highly with the Maranell (1970) and the Murray and Blessing (1983) ratings. According to Simonton's factor analysis, achievement drive has most to do with being persistent and industrious ( $\mathrm{Si}$ monton, 1987, p. 146). Simonton (1986b) also found that achievement drive correlates highly with Thorndike's (1950) measures of general activity and liking for responsibility. In turn, all of these variables appear to be related to several of Yukl's (1981) successful leader characteristics, especially persistent, energetic, willing to assume responsibility, ambitious, and achievement oriented. In addition, a strong desire to excel is recognized in Simonton's political leadership theory (1984, p. 49) as a primary factor in attaining eminence.

It seems clear that the five-variable personological equation not only has high predictive utility but also affords a rather strong capacity to sustain viable interpretation. What do the other equations tell us?

When variables from the combined personological and situa- 
tional pools were selected in free stepwise mode with the Maranell (1970) index as the criterion, the following seven-variable formula was produced:

$$
\begin{array}{r}
.37 \text { (IQ) }+.13 \text { (years in office) }+.30 \text { (achievement drive) } \\
-.30 \text { (tidiness) }+.12 \text { (height) }-.23 \text { (attractiveness) } \\
+.16 \text { (Machiavellianism) }-9.31 .
\end{array}
$$

On the average, this formula accounted for $85 \%$ of the variance in greatness as tapped by the nine greatness measures in Table 3. This equation adds Simonton's primary predictor, years in office, and Machiavellianism to the predictors already included in the preceding five-variable personological formula. It should be noted that personological variables still accounted for $83 \%$ of the total variance accounted for in the Maranell ratings when years in office was entered as the second predictor. When length of term was appended to the five-variable personological formula, it accounted for only $9 \%$ of the variance in the Maranell index.

Machiavellianism had a very high positive loading for sly and a high positive loading for shrewd in the factor analysis by $\mathrm{Si}$ monton (1986b, p. 159). At least "in the wheeling-and-dealing atmosphere of the legislative chambers, a shrewd, even sly chief executive may be more highly respected for competence" (Simonton, 1987, p. 254). To be sly and shrewd might add to leadership effectiveness, but there may also be more indirect connections. As Simonton (1986b, p. 153) points out, Alker (1981) has proposed that political creativity may be revealed through a tendency to be Machiavellian, and Simonton (1986a, p. 280) has referred to political creativity as "a potential attribute of greatness." Simonton (1986b) has found that Machiavellianism is correlated with several aspects of legislative effectiveness and Yukl (1981) does include creativity as a successful leadership characteristic. In the present study, forcefulness alone correlates with Machiavellianism. In Simonton's (1986b, p. 159) factor analysis, being energetic and active had the heaviest loadings on forcefulness and these are also characteristics of successful leaders (Yukl, 1981).

For sheer predictive capacity, the following Murray and Blessing (1983) seven-variable formula is superior to all of the formulas developed in this research and by Simonton:

$$
\begin{aligned}
.36(\mathrm{IQ})+.17 \text { (years in office) }+.35 \text { (achievement drive) } \\
\quad-.26 \text { (tidiness) }-.02 \text { (achievement motive) } \\
\quad+.10 \text { (height) }-.21 \text { (attractiveness) }-6.53 .
\end{aligned}
$$

On the average, this formula accounted for $88 \%$ of the variance in greatness across the nine indexes using the common database and accounted for $83 \%$ of the variance when using the maximum $n$ available for each of the nine indexes. The comparable Maranell equation equaled its predictive capacity in the case of the common database but fell somewhat short when the maximum number of cases for each rating was used.

What is the most reasonable order of entry for the personological, situational, and zeitgeist pool variables? As stated earlier, perhaps the most plausible way to conceptualize a hierarchy is to assume that the zeitgeist creates the milieu for a politician with certain personological characteristics to win the presidency, and the tenor of the times combined with the president's personological factors results in certain administrative outcomes such as the length of term, whether there is war, whether scandal dooms the presidency, and maybe even whether the president is assassinated. Stepwise regression with the Maranell index and this entry order produced the following formula, which contains only personological variables that surfaced in earlier equations and none of Simonton's situational predictors:

$$
\begin{aligned}
& .05 \text { (Zeitgeist } 1)+.36 \text { (achievement drive) }-.25 \text { (tidiness) } \\
& +.27(\mathrm{IQ})+.11 \text { (height) }-.21 \text { (attractiveness) }-7.77 \text {. }
\end{aligned}
$$

On the average, this formula accounted for $85 \%$ of the variance in the nine greatness ratings in Table 3. This may be the most compelling formula developed in this study because it lends itself to plausible interpretation, takes into account a rational ordering, and has high predictive capabilities.

In this research, the A. M. Schlesinger, Jr. variable has clearly demonstrated its importance to an understanding of the predictors of presidential greatness. It was extremely potent when serving as an initial predictor, accounting for half of the variance in the Maranell (1970) greatness ratings $(n=29)$, and for this selected database, Zeitgeist 1 correlated with the following: intellectual brilliance (.46), conservatism $(-.55)$, height $(.38)$, forcefulness (.50), years in office (77), and years of war (.56). As assessed with the Maranell ratings, presidential greatness also correlated with Zeitgeist 1 (70), intellectual brilliance (67), conservatism ( -.57$)$, height (.49), forcefulness (.61), years in office (.54), and years of war (.63). Evidently, men who are brighter, less conservative, taller, and more forceful tend to occupy the White House during the public purpose phases of A. M. Schlesinger, Jr's cycle, and to a significant extent these are the same men who receive the praises of historians.

Comparisons between the Simonton equations and the six key equations computed in the current study according to the value of the adjusted $R^{2}$ s are also rather informative. In descending order, the equations produced the following values for adjusted $R^{2}$ : Maranell (1970) seven-variable personologicalsituational formula (.92), Maranell six-variable personologicalsituational formula (.89), Murray and Blessing (1983) sevenvariable personological-situational formula (89), Maranell zeitgeist-first six-variable formula (88), Maranell five-variable personological formula (79), Simonton (1986b) six-variable formula (79), Simonton (1986a) five-variable formula (74), and Maranell four-variable situational formula (59). From this perspective, the Simonton equations have been surpassed.

A review of the Maranell (1970) equations constructed here shows that there is a high degree of commonality among the various formulas. Intellectual brilliance, achievement drive, height, tidiness, and attractiveness surface as predictors, with coefficient signs in the same direction when the selection is made stepwise from the personological pool only, when the selection is made stepwise from the combined personological and situational pool, or when the selection is made according to the most logical order of entry (i.e., zeitgeist, personological, and situational). In these three equations and a fourth equation that resulted from the stepwise selection of personological vari- 
ables followed by the stepwise selection of situational variables, the only other predictors are length of term, Machiavellianism, and the zeitgeist variable. It has been shown that the greatness variance accounted for by length of term is subsumed by the zeitgeist variable. Machiavellianism, although readily interpretable as a predictor, was only included in the equation on the basis of a stepwise selection from the combined personological and situational pools. As the final predictor in the equation, it contributed a marginal $2.4 \%$ to the variance accounted for in greatness-the smallest increment of any predictor in the Maranell equations. So there is a high degree of commonality in four of the five equations, and the fifth equation was restricted to situational variables.

The parallel equations developed with the Murray and Blessing index are quite similar to those calculated with the Maranell ratings, although in all except the situational equation, a somewhat smaller portion of the variance in greatness was explained. When the selection was made from the personological pool only, the same five predictors emerged as with the Maranell ratings but in a somewhat different order. When variables were selected stepwise from the combined personological and situational pools, the predictors and their order were the same except for the dropping of Machiavellianism as the seventh predictor and the insertion of achievement motive as the new fifth predictor. The largest discrepancy between the Maranell and the Murray and Blessing equations occurred when the logical order of entry was instituted. Both criterion variables produced equations with zeitgeist and achievement drive as the first two predictors, but the Maranell equation added tidiness, intellectual brilliance, height, and attractiveness, whereas the Murray and Blessing equation included assassination, war hero status, and years of war. Nevertheless, zeitgeist and achievement drive alone explained $82 \%$ of the total variance accounted for in greatness in each equation.

Perhaps attention should be drawn to the fact that the Murray and Blessing (1983) situational equation computed here with 29 presidents excludes years in office and assassination and accounts for only $67 \%$ of the greatness variance, whereas Simonton's equation, computed on 36 presidents, includes all five situational variables and explains $78 \%$ of the variance. It should be made clear that the computations to display the performance of the Simonton equations were made with Simonton's operational definition of war years rather than the one chosen in the current research, and the two differ somewhat. ${ }^{1}$ Simonton's operational definition of length of term was also used. These differences may account for the attenuated situational formula found here, but the nature of the data for the seven extra presidents and the added power of a larger number of cases also may have contributed to the discrepancy in the formulas.

Sample size in research on the presidents is necessarily restricted and the ratio of predictors to cases must always be larger than optimally desirable for multiple regression analysis. Therefore, one might expect some fluctuations in the predictors and regression coefficients that emerge, even when criterion variables are highly correlated or sample characteristics are altered in seemingly minor ways. For instance, there were some differences in the Maranell (1970) and the Murray and Blessing (1983) equations developed in this study even though the equations were computed on a common database and the two indexes of greatness were highly correlated $(r=.96)$ for the sample of presidents involved. As another example, exploratory analysis also revealed that excluding Nixon replaces scandal with achievement drive in the Simonton (1986b) six-variable equation computed on 36 cases with the Simonton data. Regression analysis with small samples and high predictor-to-case ratios is always a risky research venture.

Equations to predict presidential greatness are bound to vary to some extent if the predictors are selected from different pools that contain and do not contain variables directly or indirectly related to the criterion. Formulas may also fluctuate if different restrictions are placed on potential predictor eligibility. And, of course, predictors already added to an equation play a part in determining those that may be subsequently included. Therefore, it is not surprising that different equations have been found to predict presidential greatness with similar success. In the final analysis, it may not be possible for any one regression equation to definitively claim the antecedents of greatness. One may simply have to settle for formulas that seem to satisfy assumptions about behavioral dynamics in this context and that have been constructed on what seems to be a rational basis. However, confidence in the equations that have surfaced here should be bolstered by the relatively high degree of commonality found rather than shaken by the small discrepancies that are apparent.

What are the ramifications of the findings of the present research for the attributional model of presidential greatness articulated by Simonton (1986a, 1987)? In light of his own research results, Simonton (1986a, 1987) proposed "an attributional model that affirms that the six predictors are most informative about how historians and lay persons alike make judgements about personal attributes under conditions of limited knowledge" (Simonton, 1987, p. 214). Among the six propositions of his model are the following:

Proposition 5. Information with the highest cognitive availability is that which had the highest salience when the information was originally attended to and processed.

Proposition 6. The most salient information includes the six predictors of years in office, war, scandal, assassination, war heroism, and intelligence. (Simonton, 1987, pp. 216-217)

ToSimonton (1 986a) it seemed "curious how little of presidential greatness can be rooted, whether directly or indirectly, in the president's personal attributes" (p. 275), and this conclusion is fully understandable given the variables that entered his equations. But would this particular attributional model have been formulated by Simonton if he had produced the equations in the current study rather than those produced in his own research? No. Simonton's attributional model clearly hinges on the assumption that his six predictors are the only ones on which a comparably successful prediction equation can be

\footnotetext{
'The war-year values for each of the presidents concerned are included in the following list with the Simonton values in parentheses: J. Adams 2.23 (3), Jefferson 4.06 (4), Madison 2.88 (3), Polk 1.69 (3), Lincoln 3.99 (4), McKinley 69 (1), Wilson 4.56 (2), F. Roosevelt 3.68 (4), Truman 2.99 (4), Eisenhower .43 (0), Johnson 3.88 (5), and Nixon 4.02 (4). The two war variables were highly correlated $(r=.94, N=36)$.
} 
based, and from the results of the present research, that is an untenable position. The integrity of the specific attributional model put forth by Simonton clearly cannot remain intact when a simple count of years in office has been discredited as a primary predictor of greatness and the variance accounted for by war years, scandal, assassination, and war hero status can be efficiently subsumed by personological and zeitgeist factors.

Generally speaking, the results of the present study suggest that where historians place presidents on the continuum of greatness is related either directly or indirectly to the personological characteristics of those being rated, and that the public purpose phases of American political history are especially conducive to the election and service of presidents who exhibit the personological characteristics most related to historical acclaim. Great persons-great leaders-may indeed come to the fore to preside over momentous times in the history of the nation.

\section{References}

Alker, H. A. (1981). Political creativity. In L. Wheeler (Ed), Review of personality and social psychology (Vol. 2, pp. 167-183). Beverly Hills, CA: Sage.

Bailey, T. A. (1966). Presidential greatness. New York: Wiley.

Bemis, S. F. (1955). A diplomatic history of the United States (4th ed.). New York: Holt, Rinehart \& Winston.

Bemis, S. F. (1959). A short history of American foreign policy and diplomacy. New York: Holt, Rinehart \& Winston.

Cohen, J., \& Cohen, P. (1975). Applied multiple regression/correlation analysis for the behavioral sciences. Hillsdale, NJ: Erlbaum.

Darlington, R. B. (1972). Multiple regression in psychological research and practice. Psychological Bulletin, 77, 446-452.

Encyclopedia Americana (1984). Danbury, CT: Grolier.

Kane, J. N. (1964). Facts about the presidents (2nd ed.). New York: Wilson.

Keyes, R. (1980). The height of your life. Boston: Little, Brown.

Kinder, D. R., Peters, M. D., Abelson, R. R., \& Fiske, S. T. (1980). Presidential prototypes. Political Behavior, 2, 315-338.

Kynerd, T. (1971). An analysis of presidential greatness and "president rating." Southern Quarterly, 9, 309-329.

Leckie, R. L. (1968). The wars of America. New York: Harper \& Row.

Mann, R. D. (1959). A review of the relationship between personality and performance in small groups. Psychological Bulletin, 56, 241270.

Maranell, G. M. (1970). The evaluation of presidents: An extension of the Schlesinger polls. Journal of American History, 57, 104-113.
Matloff, M. (Ed.). (1969). American military history. Washington, DC: Office of the Chief of Military History, United States Army.

Merenda, P. F. (1964). Perception of role of the president. Perceptual and Motor Skills, 19, 863-866.

Morrow, L. (1987, March). A change in the weather. Time, pp. 28-34, 37.

Murray, R. K., \& Blessing, T. H. (1983). The presidential performance study: A progress report. Journal of American History, 70, 535-555.

Myers, J. L. (1979). Fundamentals of experimental design (3rd ed.). Toronto: Allyn \& Bacon.

Nice, D. C. (1984). The influence of war and party system aging on the ranking of presidents. Western Political Quarterly, 37, 443-455.

Nunnally, J. C. (1967). Psychometric theory. New York: McGraw-Hill.

Rossiter, C. (1956). The American presidency. New York: Harcourt, Brace.

Schlesinger, A. M. (1949). Paths to the present. New York: Macmillan.

Schlesinger, A. M. (1962, July 29). Our presidents: A rating by 75 historians. New York Times Magazine, pp. 12-13.

Schlesinger, A. M., Jr. (1986). The cycles of American history. Boston: Houghton Mifflin.

Simonton, D. K. (1981). Presidential greatness and performance: can we predict leadership in the White House? Journal of Personality, 49, 306-323.

Simonton, D. K. (1984). Genius, creativity, and leadership. Cambridge, MA: Harvard University Press.

Simonton, D. K. (1986a). Presidential greatness: The historical consensus and its psychological significance. Political Psychology, 7, 259283.

Simonton, D. K. (1986b). Presidential personality: Biographical use of the Gough Adjective Check List. Journal of Personality and Social Psychology, 51, 149-160.

Simonton, D. K. (1987). Why presidents succeed: A political psychology of leadership. New Haven, CT: Yale University Press.

Sokolsky, E. (1964). Our seven greatest presidents. New York: Exposition Press.

Thorndike, E. L. (1950). Traits of personality and their intercorrelations as shown in biography. Journal of Educational Psychology, 41, 193-216.

Winter, D. G. (1987). Leader appeal, leader performance, and the motive profiles of leaders and followers: A study of American presidents and elections. Journal of Personality and Social Psychology, 52, 196-202.

Yukl, G. (1981). Leadership in organizations. Englewood Cliffs, NJ: Prentice-Hall.

Received September 17, 1990

Revision received March 28, 1991

Accepted June 4, 1991 